\title{
Effect of sampling frequency on measurements of seasonal primary production and oxygen status in near-shore coastal ecosystems
}

\author{
Craig D. Taylor, Brian L. Howes \\ Woods Hole Oceanographic Institution, Woods Hole, Massachusetts 02543, USA
}

\begin{abstract}
New automated in situ techniques were used for high-resolution time series measurement of primary production and water column oxygen concentration in near-shore coastal marine embayments. Results revealed 2 -fold day-to-day fluctuations in measured phytoplankton production, and periodic changes in water column oxygen concentration as great as $100 \mu \mathrm{M}$ occurring in a matter of a few hours. Effects of sampling frequency upon the determination of seasonal primary production and water column oxygen status were assessed by subsampling the high-resolution measurements at various intervals and reanalyzing of the desired parameters using the lower-resolution data. Results indicate that ecosystem studies using classic measurement intervals (e.g. 30 d) may be undersampled 5- to 30-fold with respect to both primary production and oxygen concentration, resulting in serious inaccuracies in data crucial to ecological and water quality studies.
\end{abstract}

KEY WORDS: Primary production $\cdot$ Photosynthesis $\cdot$ Oxygen $\cdot$ Coastal

\section{INTRODUCTION}

Coastal and lacustrine environments are characteristically variable in their physical, chemical and biological attributes (e.g. Lewis \& Platt 1982, Nixon et al 1986, Lohrenz et al. 1987, Mantoura et al. 1988, Cole et al. 1989, Dustan \& Pinckney 1989, Mills \& Tett 1990 Sanford et al. 1990). In systems which receive significant anthropogenic nutrient inputs, the amplitude of variations in physical, chemical and biological properties is often large, especially in coastal ponds and embayments which intercept transport from land before entry into the ocean (Boynton et al. 1982, Oviatt et al. 1986, Sanford et al. 1990, Malone 1991). Concern over the effects of increased nutrient loading on coastal ecosystems through groundwater, streams and from direct waste inputs places greater importance upon effective approaches for both process level research and monitoring of these environments.

Given that events of major ecological significance may result from sporadic and short-lived perturbations in the environment (e.g. Jenkins \& Goldman 1985, Dickey 1990), research strategies should emphasize approaches that substantially increase the temporal and spatial resolution of aquatic measurements, without sacrificing the measurement longevity required for quantifying longer-term seasonal changes (Dickey 1991, Dickey et al. 1993). Unfortunately, logistical and financial constraints are often the primary elements controlling the temporal and spatial resolution of labor-intensive coastal environmental studies. The result can be an undersampling of important ecological parameters upon which investigators base their attempts to predict effects of a natural or anthropogenic change against a background of variable natural phenomena. A typical coastal or oceanographic seasonal study may consist of as few as 4 and up to approximately 12 sampling periods per year (e.g. Nixon \& Pilson 1983, O'Reilly \& Busch 1984, Rizzo \& Wetzel 1986, Lohrenz et al. 1992) within environments that may possess ecosystem-structuring periodic or stochastic events of 1 to $2 \mathrm{wk}$ duration or less. While researchers have recognized the dangers of lowfrequency sampling in variable environments, there have been few studies attempting to quantify these effects (e.g. Rizzo \& Wetzel 1986, Wiggert et al. in press). 
In order to investigate the potential role of sampling rate upon both the patterns and quantitative estimation of 2 key ecological parameters, primary production and dissolved oxygen, we conducted a highfrequency study of these parameters in a coastal embayment. By use of new automated in situ techniques and instrumentation, we were able to maintain high temporal resolution measurement of these variables for 4 to 6 mo. Large amplitude, high-frequency variability was manifest in measurements of these variables. The short period variations suggested that accurate representation of the environment may be jeopardized by the relatively low temporal resolution sampling programs generally employed in most ecology studies.

\section{METHODS}

Study areas. Photosynthesis and bottom water oxygen concentration measurements were conducted in the central $1.6 \mathrm{~m}$ deep region of a coastal embayment of Vineyard Sound, Little Pond, located in Falmouth, Massachusetts, USA. Bottom water oxygen measurements were also made at a near-shore (approximately $2 \mathrm{~km}$ from land; $\left.41^{\circ} 33.30^{\prime} \mathrm{N}, 70^{\circ} 51.99^{\prime} \mathrm{W}\right)$ station (depth $8.1 \mathrm{~m}$ ) in Buzzards Bay in the vicinity of New Bedford Harbor, Massachusetts.

Time series photosynthesis measurements. Phytoplankton photosynthetic production was measured in Little Pond using a Submersible Incubation Device (SID; Taylor \& Doherty 1990). The instrument conducted three $3 \mathrm{~h}$ incubation experiments in situ at $0.6 \mathrm{~m}$ depth. Samples were incubated with approximately $50 \mu \mathrm{Ci}$ of ${ }^{14} \mathrm{C}$-bicarbonate at final specific activities ranging between 0.06 and $0.1 \mu \mathrm{Ci} \mu \mathrm{mol}^{-1}$, depending upon dissolved inorganic carbon (DIC) concentrations in the environment at the time of the experiment. DIC was determined by headspace analysis of acidified samples using an infrared analyzer and ranged between 1.2 and $2.1 \mathrm{mM}$ (final concentration of ${ }^{14} \mathrm{C}$-tracer approximately $\left.2.2 \mu \mathrm{M}\right)$. During each of the 3 incubations, 4 subsamples (12 subsamples per deployment) were chemically fixed in situ to provide a timecourse measure of photosynthetic carbon fixation. The 3 subsamples used for photosynthetic rate measurements were fixed 5,85 and 170 min into the incubation with sulfuric acid, $0.23 \mathrm{~N}$ final concentration, and the remaining subsample used for determination of radiotracer specific activity was taken 10 min into the incubation and fixed with $\mathrm{NaOH}$ at a final concentration of $0.07 \mathrm{~N}$. At the end of each 3-incubation deployment the instrument was brought to the laboratory for processing of subsamples. Acid non-volatile ${ }^{14} \mathrm{C}$ was determined by sparging $10 \mathrm{ml}$ samples with air for
30 min prior to mixing with $10 \mathrm{ml}$ Aquasol Il and analysis on a United Technologies Packard Tri-Carb 4000 series scintillation spectrometer (external standard correction for quench). Tracer specific activity was determined by mixing 0.1 or $0.2 \mathrm{ml}$ aliquots with $0.2 \mathrm{ml}$ hyamine hydroxide and counting in $10 \mathrm{ml}$ Aquasol II. Two modes of SID incubation were implemented, (1) a time series mode where the $3 \mathrm{~h}$ incubations were centered on solar noon and conducted at 1 or $2 \mathrm{~d}$ intervals and (2) a 'back-to-back' mode where three $3 \mathrm{~h}$ incubations were conducted sequentially during a $9 \mathrm{~h}$ interval covering $95 \%$ of the daily light period to provide a measure of whole-day production. The back-to-back incubations were conducted at 2 to 4 wk intervals.

Coupled with the 'back-to-back' SID incubations were parallel $9 \mathrm{~h}$ time-course in situ bottle incubations conducted at $0.25,0.45$ and $0.8 \mathrm{~m}$ depth. Water to be incubated was pumped from the selected depth via a peristaltic pump into $300 \mathrm{ml}$ BOD bottles under subdued light and $12.5 \mu \mathrm{Ci}$ of ${ }^{14} \mathrm{C}$-bicarbonate introduced to yield a final specific activity ranging between 0.015 and $0.025 \mu \mathrm{Ci} \mathrm{mol}^{-1}$ as discussed above. Within minutes 4 replicate bottles were returned to the depth of sample procurement for incubation. At 4.5 and 9 h into the incubation duplicate bottles were removed from each of the 3 depths, placed in the dark, and within $30 \mathrm{~min}$ duplicate $100 \mathrm{ml}$ samples from each bottle filtered through Whatman GF/F glass fiber filters to provide a time-course measure of photosynthesis. Two additional bottles were retained in the dark for determination of zero time activity. The moist filters were fumed with $\mathrm{HCl}$ vapors for approximately $30 \mathrm{~min}$ in closed petri dishes, dried overnight, and analyzed in $10 \mathrm{ml}$ Aquasol II by scintillation spectroscopy. Dark bottle activities were small $(<1 \%$ of midday light bottle activity) and subtracted from values obtained in the light.

Regression analysis of a 10 point, 3 h time-course SID incubation revealed that individual subsamples taken from the sample incubating within the same incubation chamber could be analyzed to within a coefficient of variation (CV) of $\pm 5 \%$ (analytical CV, standard deviation $/$ mean $\times 100 \%$ ). A dual-chamber version of the SID was used to determine the precision of a typical in situ incubation. Two identical chambers were mounted parallel to one another at the same depth with the inlets approximately $20 \mathrm{~cm}$ apart. Sample was simultaneously drawn into the 2 replicate chambers and parallel time-course measurements of photosynthesis conducted. In an environment similar to Little Pond (Salt Pond, Falmouth, MA; Lohrenz 1985), incubations $(n=7)$ performed by this device at various times of the year indicated that replicate production rate measurements possessed a CV of less than $\pm 11.5 \%$. Replicate bottle incubations $(n=37)$ agreed to within a $C V$ of 
$\pm 15 \%$. These error estimates on production rates integrate both the analytical error and the betweensample error, and can be thought of as the precision of the photosynthetic measurement.

Time series oxygen measurements. Dissolved oxygen concentration was measured in Little Pond $15 \mathrm{~cm}$ above the sediment surface at 15 min intervals using a Pulsed Oxygen and Temperature Recorder [Endeco Type 1184 (T-1184), based on principles developed by Langdon 1984]. The oxygen polarographic measurement was made only during the few hundred millisecond interval that the electrode was 'pulsed on'. The remainder of the time (15 min) the electrode was 'off' and re-equilibrating with the environment. Biofouling of the electrode Teflon membrane was prevented by routine cleaning and application of a thin film of a tributyl tin wax (which was always kept moist during transport).

Oxygen and temperature data were retrieved from the T-1184 solid-state data cartridges at approximately $10 \mathrm{~d}$ intervals when the instrument was brought to the laboratory for recalibration. Oxygen molar concentration was computed from oxygen partial pressure and temperature measurements made by the sensors, average salinity $(27.5 \pm 5.0 \mathrm{ppt}$ ) determined from samples independently taken at 1 to $3 \mathrm{~d}$ intervals, electrode calibration coefficients, and algorithms for incorporating effects of salinity, temperature and hydrostatic pressure (sensor depth) upon determined oxygen solubility (Benson \& Krause 1984). Percent oxygen saturation was determined from the ratio of measured oxygen concentrations to theoretical water column saturation computed from oxygen solubility algorithms (Benson \& Krause 1984), sensor measurements of water column temperature, the above-determined salinity and average barometric pressure measured at the nearby laboratory in Woods Hole, Massachusetts.

The T-1184 sensor was initially calibrated at 2 oxygen partial pressures (air saturated and approximately half air-saturated partial pressures) at each 2 temperatures $\left(25\right.$ and $10^{\circ} \mathrm{C}$ ). Electrode offset drift was corrected by routine calibrations performed at the beginning and end of each nominal $10 \mathrm{~d}$ deployment by immersion of the sensor in a temperature-controlled distilled water bath that was maintained in equilibrium with the atmosphere. Oxygen molar concentration in the calibration bath was determined by a solubility algorithm (Benson \& Krause 1984) and measurements of bath temperature and barometric pressure within the laboratory. Measurement precision of the T-1184 sensor was $\pm 0.8 \mu \mathrm{M}$, permitting a statistically significant resolution of $2.5 \mu \mathrm{M}$. Calibration drift was a linear $+5 \mu \mathrm{M} \mathrm{mo}^{-1}$ and a linear correction for sensor drift was applied to the data. On several occasions throughout the study period, the water column in Little Pond came into equilibrium with the atmosphere and provided an in situ check on sensor calibration. Agreement between sensor measurements and environmental equilibrium oxygen concentrations were typically within $\pm 7 \mu \mathrm{M}$.

Bottom water oxygen concentration was also measured at a near-shore station in Buzzards Bay near New Bedford Outer Harbor. Oxygen, temperature and conductivity recorders ( $\mathrm{T}-1184 \mathrm{C})$ were located $30 \mathrm{~cm}$ from the sediment surface and measurements made at 15 min intervals. Oxygen concentration was computed as described above with the exception that parallel salinity determinations were incorporated into the algorithms. Calibration and correction for sensor drift was carried out as described above at nominal $14 \mathrm{~d}$ intervals. Percent oxygen saturation was computed as described above from sensor measurements of oxygen, temperature and conductivity (salinity), and barometric pressure measured by an Endeco Inc. meteorological and wave monitoring buoy located within $2 \mathrm{~km}$ of the station. Sensor oxygen concentration measurements were compared with Winkler titrations made at $1 \mathrm{wk}$ intervals at the same location and depth. Agreement was within $\pm 11 \mu \mathrm{M}$. A portion of this error was attributable to effects of the small uncertainty in the time base between sensor readings and time of water sample collection for the Winkler analyses.

Chlorophyll a measurements. Samples were filtered through $0.45 \mathrm{\mu m}$ Millipore filters, extracted in cold $90 \%$ acetone, and chlorophyll a determined from absorbance measurements and trichromatic equations (Parsons et al. 1984).

\section{RESULTS AND DISCUSSION}

\section{Phytoplankton production}

Results of typical whole- and midday SID phytoplankton production measurements are shown in Figs. 1 \& 2. In most instances production was linear during the 3 h time-course incubations (e.g. Figs. 1B \& $2 \mathrm{C}, 5$ out of 6 cases shown). Initial and average rates were, in fact, coincident in over $90 \%$ of the 70 production measurements (Fig. 2D, solid and dashed lines). Periodic intercalibration measurements between SID and bottle incubations yielded similar rates of carbon incorporation which were linear throughout the $9 \mathrm{~h}$ time course (e.g. Fig. 1C, compare circles and squares). Production rates determined by the 2 methods at various times of the year (Fig. 2D) were not significantly different in 5 out of 6 cases ( $t$-test; Julian Days 165, 171, 181, 206 and 213, $p>0.05$ ). A significant difference was manifest on Julian Day $153(p=0.05)$. The reason for the difference on Julian Day 153 is not known, but 

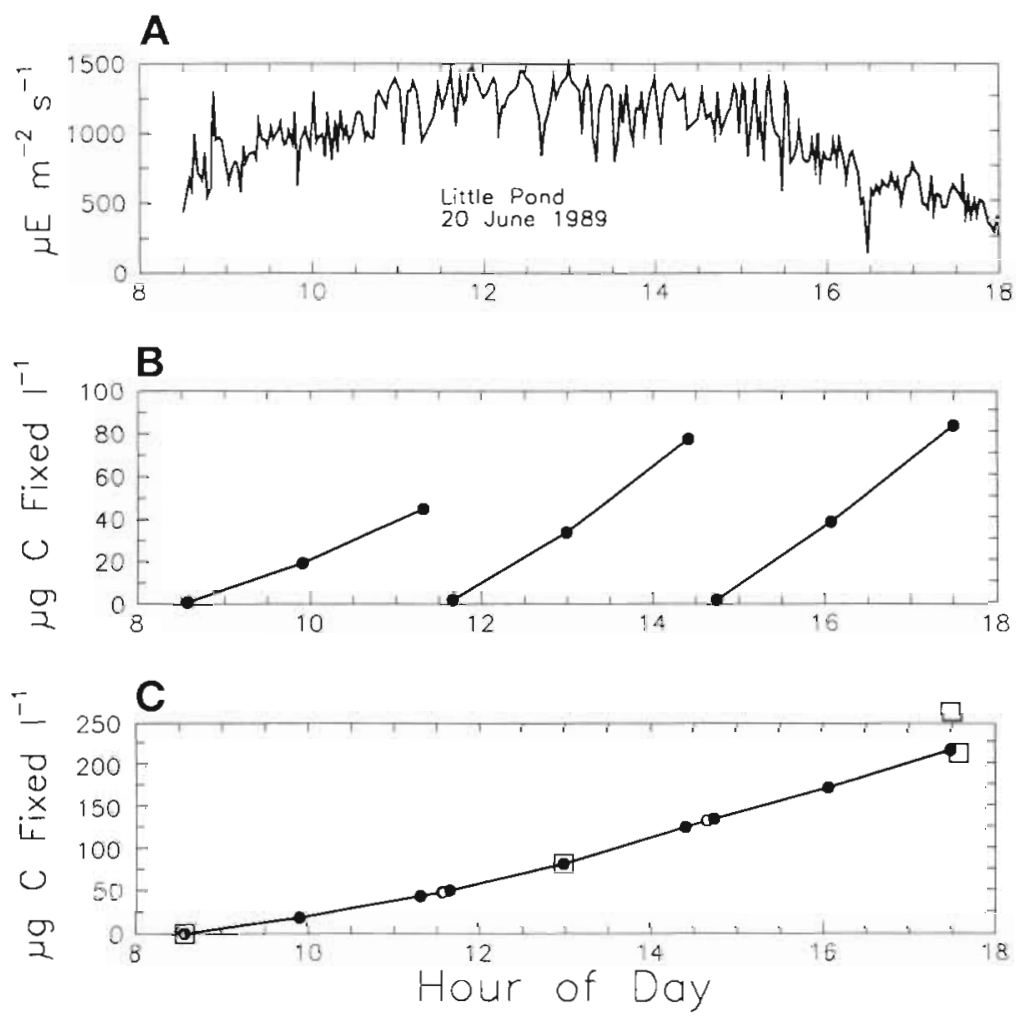

Fig. 1. Phytoplankton production determined at $0.6 \mathrm{~m}$ depth in Little Pond from three $3 \mathrm{~h}$ back-to-back in situ SID incubations and parallel in situ bottle incubations. (A) In situ light intensity recorded at 2 min intervals by a $2 \pi$ PAR sensor on the SID. (B) Phytoplankton production determined during each of 3 SID incubations. (C) Algebraic summation of the activities measured during the 3 back-to-back SID incubations in (B) to provide a measure of whole-day phytoplankton production. $\square$ : results of time-course bottle incubations where samples were obtained from the environment at 08:30 h and incubated in situ for 4.5 and $9.0 \mathrm{~h}$. Photosynthesis rates determined 4.5 and $9.0 \mathrm{~h}$, respectively, into the incubation by the SID $(18.3 \pm 2.1$ and $23.0 \pm 2.7 \mu \mathrm{g} \mathrm{C} \mathrm{l}^{-1} \mathrm{~h}^{-1}$, standard deviation as described in 'Methods') were not significantly different from companion bottle incubations (18.7 \pm

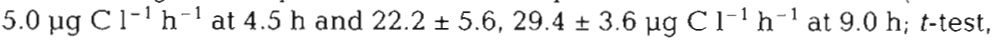
$\mathrm{p}>0.05$ in all comparisons). 0 : extrapolated zero time data points, as the earliest subsample is obtained 5 min after initiation of the incubation, rather than at true zero time. There is also a small gap between the end of a given incubation and the beginning of the next (time required for in situ cleaning of the incubation chamber), requiring that the curve of the previous incubation be extrapolated to the time that the next incubation begins. The extrapolated zero time data point of a given incubation is aligned with the extrapolated curve of the previous incubation to provide a true estimate of cumulative production

is not likely due to large heterogeneity in activity or biomass distribution as three $3 \mathrm{~h}$ back-to-back SID measurements made throughout the photoperiod did not vary by more than $11 \%$ (mean activity and standard deviation, $16.5 \pm 1.8 \mu \mathrm{g} \mathrm{Cl}^{-1} \mathrm{~h}^{-1}$ ). Confinement of samples from this environment for the majority of the light period did not measurably affect phytoplankton activity.

A high degree of day-to-day variability was found throughout the study which was significantly greater (F-test, $\mathrm{p}<0.001$ ) than can be accounted for by SID performance $(\mathrm{CV}=11.5 \%)$. The variation in primary production measured was highest in late spring-early summer (Julian Days 150 to $200 ; \mathrm{CV}=101 \%$ ) and lower during the midsummer season (Julian Days 200 to $260 ; \mathrm{CV}=60 \%$ ), with a weighted average CV of $89 \%$. Throughout the summer and early fall much of the variation was due to up to 2 -fold day-today differences in production rates.

The majority of measured photosynthetic carbon fixation occurred during a bloom of Olisthodiscus sp. in late July through August. Throughout the JuneSeptember period there was a general lack of correlation between measured production rates and cumulative in situ light exposure during the $3 \mathrm{~h}$ incubations (linear regression; $\mathrm{n}=53, \mathrm{r}^{2}=0.045, \mathrm{p}=$ 0.75). Chlorophyll-specific production versus cumulative in situ light also showed poor agreement (linear regression, $\mathrm{n}=25, \mathrm{r}^{2}=0.25, \mathrm{p}=0.23$ ), suggesting that the system was usually light-saturated. This is supported by the observation that photosynthesis rates obtained by back-to-back SID incubations were not significantly different from one another throughout the day (Fig. 2D, large open circles on Julian Days 153 and 206; t-test, $\mathrm{p}>0.05,6$ comparisons), even though in situ light typically varied by up to 2 -fold. Morning activity $\left(16.2 \pm 1.7 \mu \mathrm{g} \mathrm{Cl}^{-1} \mathrm{~h}^{-1}\right)$ on Julian Day 171 (Fig. 1B) was not significantly different from midday activity $\left(25.5 \pm 2.9 \mu \mathrm{g} \mathrm{C} \mathrm{l}^{-1} \mathrm{~h}^{-1}, \mathrm{p}>0.05\right)$ but was significantly lower $(p<0.05)$ than activities measured in the afternoon $(28.6 \pm 3.3$ $\left.\mu \mathrm{g} \mathrm{Cl}^{-1} \mathrm{~h}^{-1}\right)$. The trend, however, was still not correlated with cumulative light exposure (Fig. $1 \mathrm{~A} ; 11.9,15.2$ and $8.4 \mathrm{E} \mathrm{m}^{-2}$ for the $3 \mathrm{~h}$ morning, midday and afternoon incubations respectively). Nor was the difference likely attributable to non-representative sampling of the site or local biomass heterogeneity as results from both SID and bottle incubations reflected the same trend (Fig, 1C). During the June-July period (Julian Days 150 to 210) photosynthesis activity (Fig. 2D, bottle incubations, open squares) was also invariant with depth (1-way ANOVA; F-ratio, $\mathrm{df}_{2,12}=1.01, \mathrm{p}=0.61$ ).

In contrast, during the bloom (Julian Days 211 to 228)

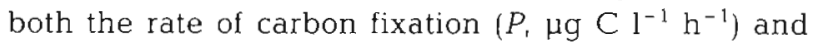
chlorophyll-specific production $\left[P_{\text {chl. }} \mu \mathrm{g} C(\mu \mathrm{g} \mathrm{chl} a)^{-1}\right.$ $\mathrm{h}^{-1}$ ] appeared to be related to integrated in situ light ( $\left.L t\right)$ 
Fig. 2. Time series SID measurements of midday production on 3 consecutive days in Little Pond. (A, B) In situ light recorded by the SID as in Fig. 1 (C) $3 \mathrm{~h}$ midday measurements of phytoplankton production. (D) Midday photosynthesis rates determined from 70 SID incubations and 6 time-course in situ bottle incubations. $0,-\cdots$ : initial photosynthesis rates determined from the first $1.5 \mathrm{~h}$ of the incubation; $\bullet, \ldots$ : rates determined from the full $3 \mathrm{~h}$ incubation; $\bigcirc$ : morning, midday and afternoon photosynthesis rates determined from three $3 \mathrm{~h}$, back-to-back SID incubations as illustrated in Fig. 1. B; $\square$ : photosynthesis rates at $\mathrm{SID}$ incubation depths determined from in situ bottle incubations conducted on the same day as back-to-back SID incubations
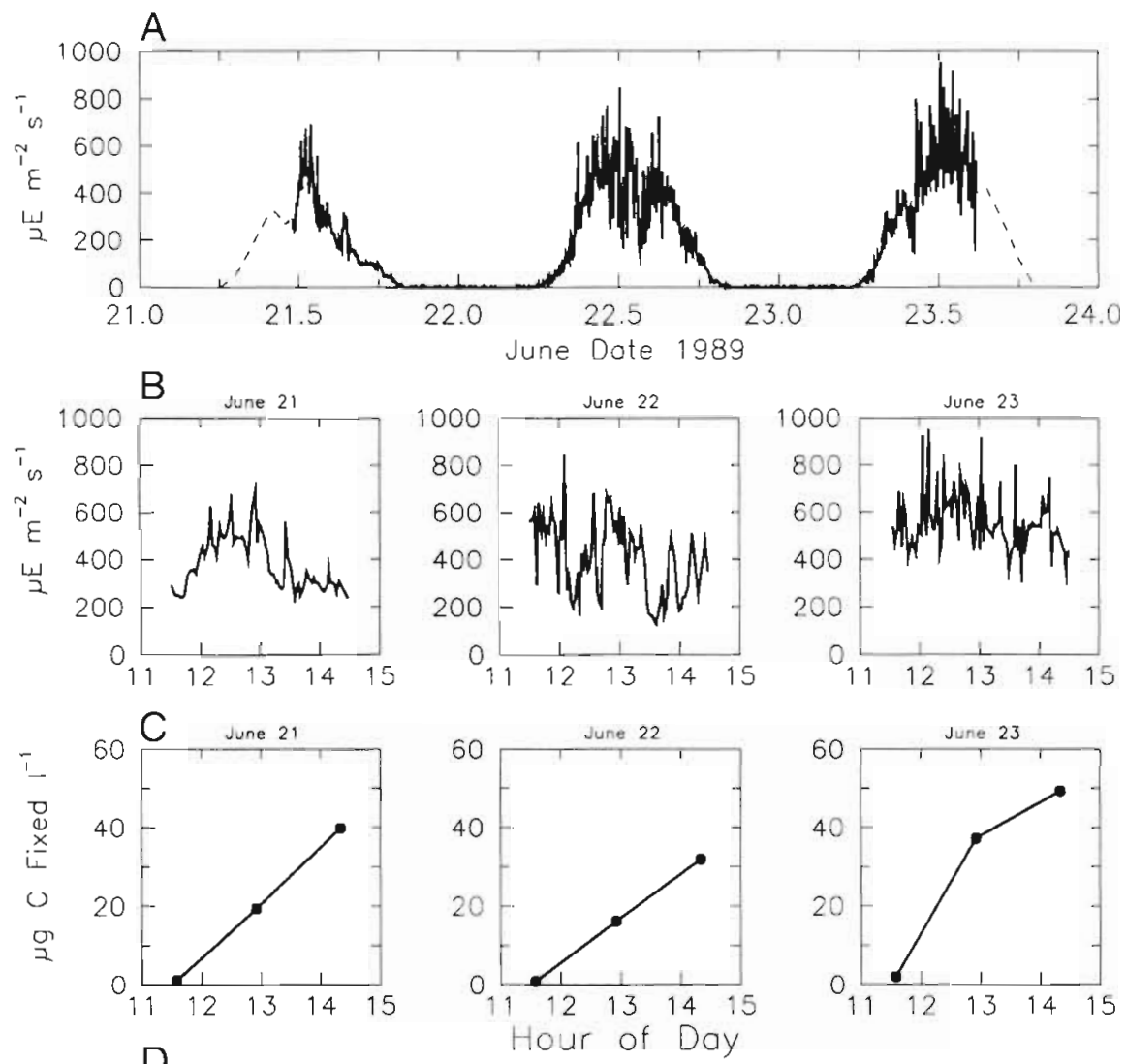

$\mathrm{D}$

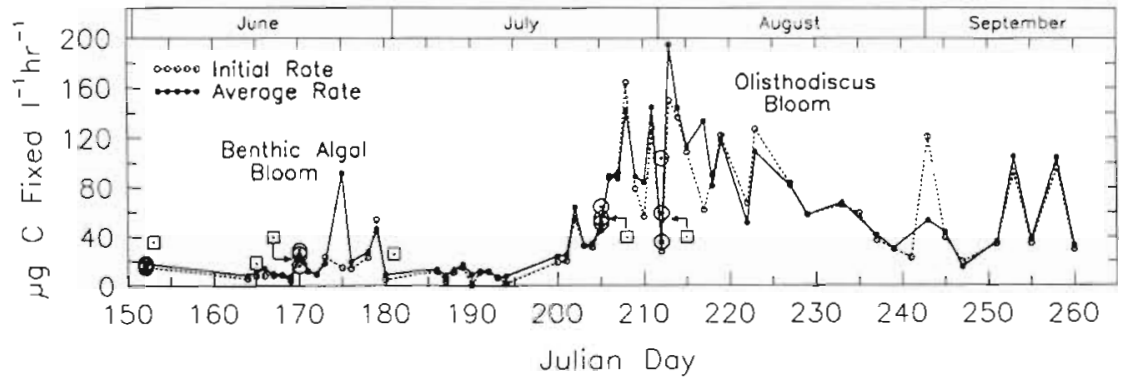

(linear regressions $P=m L t+b$, where $m=10.3 \pm 2.2$, $b=25.7 \pm 18.6, \mathrm{n}=12, \mathrm{r}^{2}=0.83, \mathrm{p}<0.001$; or $P_{\text {chl }}=$ $m L t+b$, where $m=0.84 \pm 0.33, b=1.1 \pm 1.3, \mathrm{n}=8, \mathrm{r}^{2}=$ $0.72, p<0.05$ ), indicating that production was light limited. Activity determined throughout the day by backto-back SID incubations also reflected this trend (59.1, 35.7 and $103 \mu \mathrm{g} \mathrm{C}$ fixed $\mathrm{l}^{-1} \mathrm{~d}^{-1}$ when cumulative in situ light was $5.7,4.7$ and $6.1 \mathrm{E} \mathrm{m}^{-2}$ for the $3 \mathrm{~h}$ morning, midday and afternoon measurements respectively; Fig. 2D, large open circles, Julian Day 213). The presence of light limitation during the bloom was supported by the exponential decrease in photosynthetic activity with depth [log-linear regression $\ln \left(P_{d}\right)=\ln \left(P_{0}\right)-k d$; where $P_{0}$ and $P_{d}$ are the production rates at the surface and depth $d_{1}$ and constant $k=2.20 \pm 0.34 \mathrm{~m}^{-1} ; \ln \left(P_{0}\right)=5.35 \pm$ $0.23 ; \mathrm{n}=7, \mathrm{r}^{2}=0.94, \mathrm{p}<0.001$; bottle and SID incubations on Julian Day 213, 6 depths, 2 stations].
SID-based, depth-integrated algal primary production in Little Pond over the 4 mo summer period is shown in Fig. 3A. Except for the peak of the Olisthodiscus bloom, light-saturated photosynthesis permitted depth-integrated production $\left(A_{1}, \mathrm{~g} \mathrm{C} \mathrm{m}^{-2} \mathrm{~d}^{-1}\right)$ to be determined from the $3 \mathrm{~h}(1 / 3$ of the $9 \mathrm{~h}$ photoperiod $)$ midday SID measurements made at $0.6 \mathrm{~m}$ depth $\left[A_{\mathrm{m}}\right.$, $\left.g \mathrm{C}^{-1}(1 / 3 \mathrm{~d})^{-1}\right]$. Whole-day production at the SID incubation depth of $0.6 \mathrm{~m}\left(A_{0.6}, \mathrm{~g} \mathrm{C}^{-1} \mathrm{~d}^{-1}\right)$ was computed according to the formula $A_{0.6}=3 A_{\mathrm{m}}$. Depth-integrated production was determined over the $1.6 \mathrm{~m}$ water column from: $A_{1}=A_{0.6} \times 1.6[\mathrm{~m}] \times 1000\left[1 \mathrm{~m}^{-3}\right]$. During the light-limited bloom period (Julian Days 211 to 228), whole-day production was determined from summation of midday SID measurements made at $0.6 \mathrm{~m}$ depth, and proportional morning and afternoon production computed from cumulative in situ light. Inte- 


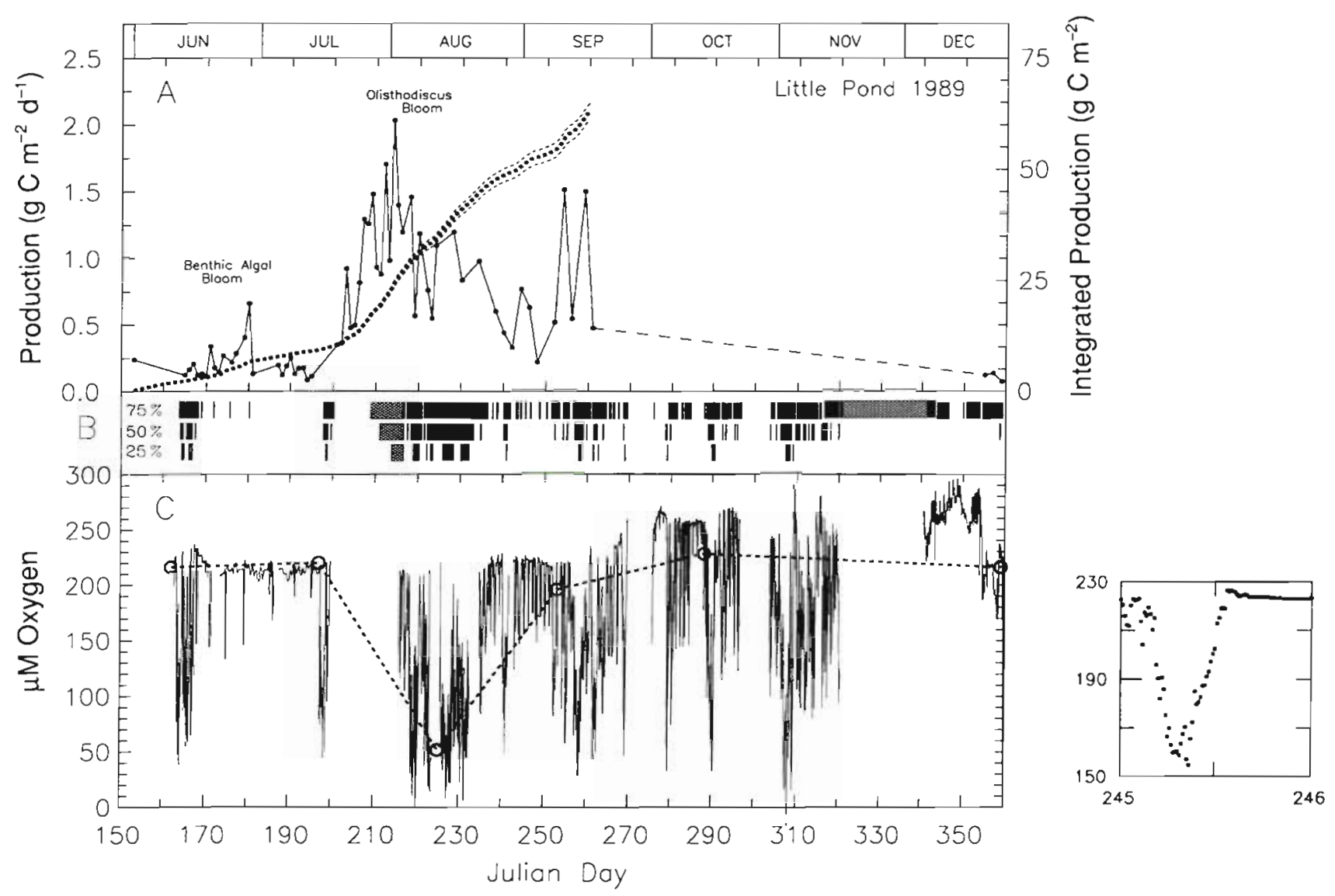

Fig. 3. Depth-integrated phytoplankton production and bottom water dissolved oxygen in Little Pond during summer and fall. (A) Phytoplankton production $(\bullet$ ) and integrated production with associated error (itii). The error in integrated production was determined by the association of a $\pm 23 \%$ random variability $(2 \mathrm{CV} ; 2$ standard deviations / mean $\times 100 \%$; see also 'Methods') to each of the original data points and integration of the resultant seasonal production curve, repeating the process 50 times, and the standard deviation of the resultant family of integrals determined. The resultant $2 \mathrm{CV}$ of seasonal production was found to be $\pm 3 \%$. (B) Solid horizontal bars delineate the periods that the bottom water oxygen concentration was equal to or below 75,50 and $25 \%$ of atmospheric equilibrium. Hatched areas represent estimated periods of oxygen depletion during intervals when data were not collected (determined in part from the oxygen status on either side of the data gap). (C) Bottom water oxygen concentration measured in situ. O: Winkler oxygen analyses of midmorning samples collected at $1 \mathrm{~m}$ depth at 30 to $70 \mathrm{~d}$ intervals which illustrate the potential ineffectiveness of low-frequency oxygen measurements representing the true oxygen status in variable ecosystems. Small panel to right: an enlargement of a 24 h section of the data in August (Julian Day 245)

grated production $\left(A_{\text {int }}, \mathrm{g} \mathrm{C} \mathrm{l}^{-1} \mathrm{~d}^{-1} \mathrm{~m}\right)$ was computed from the equation $A_{\text {int }}=A_{0} / k\left(1-\mathrm{e}^{-k d}\right)$. Surface activity $\left(A_{0}, \mathrm{~g} \mathrm{C}^{-1} \mathrm{~d}^{-1}\right)$ was determined from the relationship $A_{0}=A_{0.6} \mathrm{e}^{k d}$ ) derived from the exponential relationship described above for Julian Day 213, which given the SID incubation depth, $d=0.6 \mathrm{~m}$ and $k=2.2 \mathrm{~m}^{-1}$, yields $A_{0}=3.74 A_{06} . A_{1 \mathrm{~m}}$ was calculated given water column depth $d=1.6 \mathrm{~m}$ and $k=2.2 \mathrm{~m}^{-1}$, and the desired parameter, depth-integrated production $\left(A_{i}\right)$, was then computed from the following relationship: $A_{\mathrm{i}}=A_{\text {int }} \times$ $1000\left[1 \mathrm{~m}^{-3}\right]$.

Because of the shallowness of the environment and the uniformity of activity throughout the water column of Little Pond most of the time, the pattern of depth-integrated photosynthesis (Fig. 3A) was very similar to that observed when expressed on a volu- metric basis (Fig. 2D). Major features of the depth-integrated measure are, as before, the dominance of the summer bloom and the high-frequency variability of measured production rates. Most of the variability in the photosynthetic measurements in Little Pond was apparently due to fluctuations in algal biomass as determined by chlorophyll a concentrations. Although in situ light appeared to become limiting during the bloom maximum, changes in in situ light intensity generally described only marginally more of the variation in measured photosynthesis than chlorophyll concentration alone in stepwise multiple regression $\left(r^{2}=0.938\right.$ vs 0.943 respectively; Zar 1974), and suggests that phytoplankton self-shading was likely occurring. Similar 2- to 3-fold differences in photosynthesis between consecutive days were also found in a 
study of carbon fixation by a benthic microalgal community (Rizzo \& Wetzel 1986), and a 1 mo study describing daily photosynthesis in an oligotrophic lake also exhibited 3 -fold variations between days (Cole et al. 1989)

\section{Bottom water oxygen status}

Oxygen concentration was determined near the sediment surface in Little Pond as a measure of oxygen conditions experienced by infaunal communities. There was a large and high-frequency fluctuation in bottom water oxygen, resulting from a complex of physical and biological phenomena (Fig. 3C). During the 1989 June-December measurement period there were 5 to 8 sustained periods of hypoxia, as defined by observed oxygen concentrations below $50 \%$ of atmospheric equilibrium (Fig. 3B). There were a weeklong event in mid-June, a 3 wk event between July and August, and several-day events in September, October and November. Much of the observed fine structure resulted from fluctuating wind-driven vertical mixing effects during periods of weak watercolumn stratification as well as effects of clouds and rain storms. Rapid increases in oxygen were on occasion correlated with tidally mediated inputs of dense, cold, oxygenated water from Vineyard Sound (e.g. Julian Days 165, 309, 315 and 317). However, temporary stratification occasionally followed such cold water inputs, resulting in subsequent and rapid oxygen depletion due to the high rates of respiration in the sediments and overlying water column (summer rates and standard deviation, $116 \pm 39 \mathrm{mmol} \mathrm{m}^{-2} \mathrm{~d}^{-1}$ and $46 \pm 11 \mu \mathrm{mol} \mathrm{l}^{-1} \mathrm{~d}^{-1}$, as measured via bell jar sediment and dark bottle water column incubations, respectively; D. R. Schlezinger \& B. L. Howes unpubl. data).

The most sustained oxygen depletion was clearly correlated with the decline of the approximately 6 wk Olisthodiscus sp. bloom where the average rate of photosynthesis was 10 -fold higher than in non-bloom periods. The average bottom water oxygen concentration ranged below $100 \mu \mathrm{M}$ during much of the bloom, often below $50 \mu \mathrm{M}$. On 2 occasions the system became briefly anoxic (Julian Days 220 and 308). During and after the Olisthodiscus bloom the physical and biological processes of oxygen resupply were barely able to keep up with the oxygen demand of the environment. Rapid diel changes in oxygen were attributable to the effects of night respiration and daytime photosynthesis (Fig. 3C, small panel). Windenhanced air-sea exchange often brought the water column into equilibrium with the atmosphere (e.g. the nearly constant concentration of oxygen observed during afternoon and early evening hours; Fig. 3C. small panel).

\section{Effect of sampling frequency upon accuracy oi seasonal production measurements}

In order to investigate the effects of lower sampling rates upon determinations of seasonal production in near-shore coastal ecosystems, a series of subsampling routines were executed. Data were extracted or 'sampled' from the high-resolution studies to simulate sampling intervals of 5 to $30 \mathrm{~d}$, and the lowerresolution data set used to compute cumulative production. To simulate a real sampling program a variability of $\pm 2 \mathrm{~d}$ was randomly associated with the time base to provide a data set with a specified 'nominal' sampling interval $(5,7,14$ and $28 \mathrm{~d})$. Integrated seasonal production from subsampled results (50 repetitions simulating results of 50 independent laboratories) were compared with the 'actual' values obtained from the measured high-frequency data set. Results indicate that the sampling frequencies commonly employed in coastal studies degrade the accuracy of seasonal production measurements (Fig. 4). Measurements made at $28 \mathrm{~d}$ intervals, for example, yielded integrated summer-fall production ranging between 59 and $100 \mathrm{~g} \mathrm{C} \mathrm{m}^{-2}$, a potential 1.7 fold variation in activity simply based upon the sequence of days that the incubations were conducted (Fig. 4D; Rizzo \& Wetzel 1986). Biases in the probability of an assemblage of analyses to overestimate or underestimate true production (Fig. 4A, small panel) can result when employed nominal sampling intervals (e.g. $>20 \mathrm{~d}$ ) begin to approach the temporal scale of major activity events such as the summer bloom (approximately $50 \mathrm{~d}$ in Little Pond). Errors in computed seasonal production diminish as the frequency of sampling increases (Fig. 4A to C, small panel), but it is not until sampling intervals of $5 \mathrm{~d}$ or less that sampling-frequency-induced error begins to approach the limit of the method. Though only a portion of the seasonal cycle was analyzed in this exercise the conclusions will be unaffected as the remainder of the annual cycle in Little Pond was characterized by much lower production rates (C. D. Taylor unpubl. results from the following year).

In a recent study of effects of undersampling on gross primary production computed from high temporal resolution (minutes) measurements of chlorophyll and photosynthetically active radiation (PAR) (Wiggert et al. in press), $30 \mathrm{~d}$ sampling in oceanic and coastal regions characterized by large amplitude variability and shortterm blooms was found to result in $\geq \pm 30 \%$ errors in estimated annual production, values commensurate with that found in the coastal embayment of this study ( $\pm 35 \%, 2$ CV; Fig. 4, small panel). 


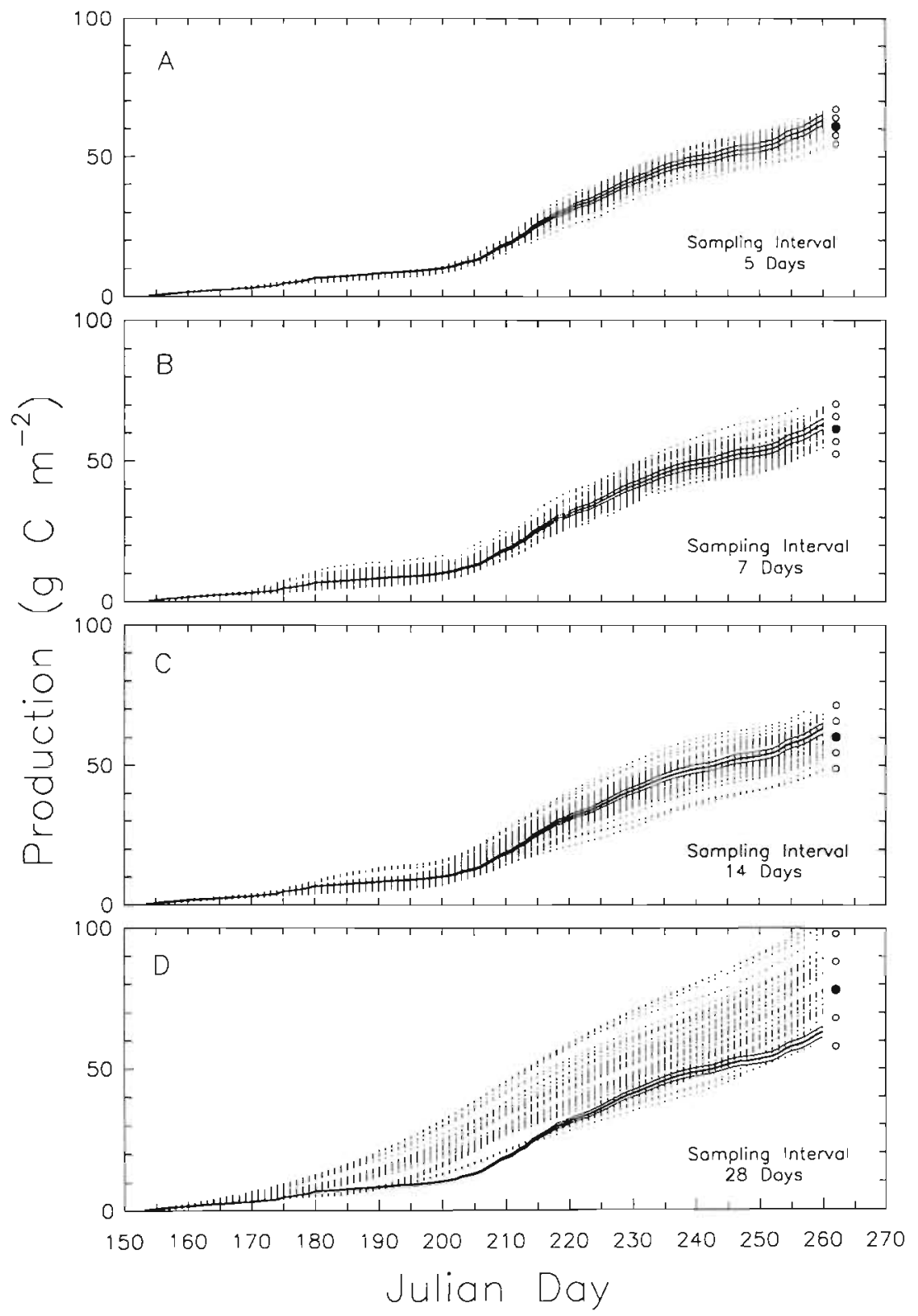

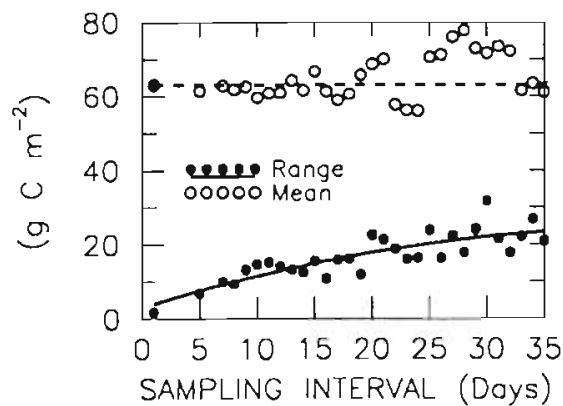

Fig. 4. Effect of sampling interval upon determined summer phytoplankton production. Solid lines represent the cumulative production and associated error (see legend of Fig. 3) throughout the summer period in Little Pond determined from high-resolution data (Fig. 3A). Dotted lines represent cumulative production from each sampling schedule obtained by subsampling the high-resolution data set at the indicated interval plus or minus a randomly selected variability in the exact day of sampling: $\pm 1 \mathrm{~d}$ at a sampling interval of $5 \mathrm{~d}(\mathrm{~A})_{i} \pm 2 \mathrm{~d}$ at sampling intervals $7 \mathrm{~d}(\mathrm{~B})$, $14 \mathrm{~d}(\mathrm{C})$ and $28 \mathrm{~d}(\mathrm{D})$. The subsampling and integration procedure was repeated 50 times to simulate results obtained if that many independent laboratories made measurements at the indicated nominal intervals. -: mean summer production determined from the 50 hypothetical studies. o: 1 and 2 standard deviations. Small panel to right: effect of sampling interval upon determined mean and range

\section{Efiect of sampling frequency upon determinations of water column oxygen status}

In contrast to primary production, where cumulative carbon fixation throughout the annual cycle is the parameter desired, measurements of dissolved oxygen in relation to effects on infaunal populations, or for purposes of water quality assessment, require the determination of the magnitude and duration of hypoxia. Given that relatively short-term depletion of this important respiratory gas can have devastating effects on the resident biota, the appropriate assessment of its concentration is critical to understanding the coupling of nutrient and organic matter loading to effects on animal communities (e.g. Oviatt et al. 1986, Costa et al. 1992, Dauer et al. 1992).

To assess potential effects of sampling frequency upon determined periods of oxygen depletion, data were repetitively extracted (10 times to simulate results from 10 independent laboratories) from the highresolution data set (Fig. $3 \mathrm{C}$ ) at 2 times during the day, 08:00 or 15:00 h, and at nominal sampling intervals of 1, 7,14 and $28 \mathrm{~d}$ (Fig. 5). The subsampling protocol was as for the primary production estimates. The periods of time when the lines connecting points of the lowerresolution data set fell below $50 \%$ of atmospheric equilibrium are indicated by the thin horizontal bars. 


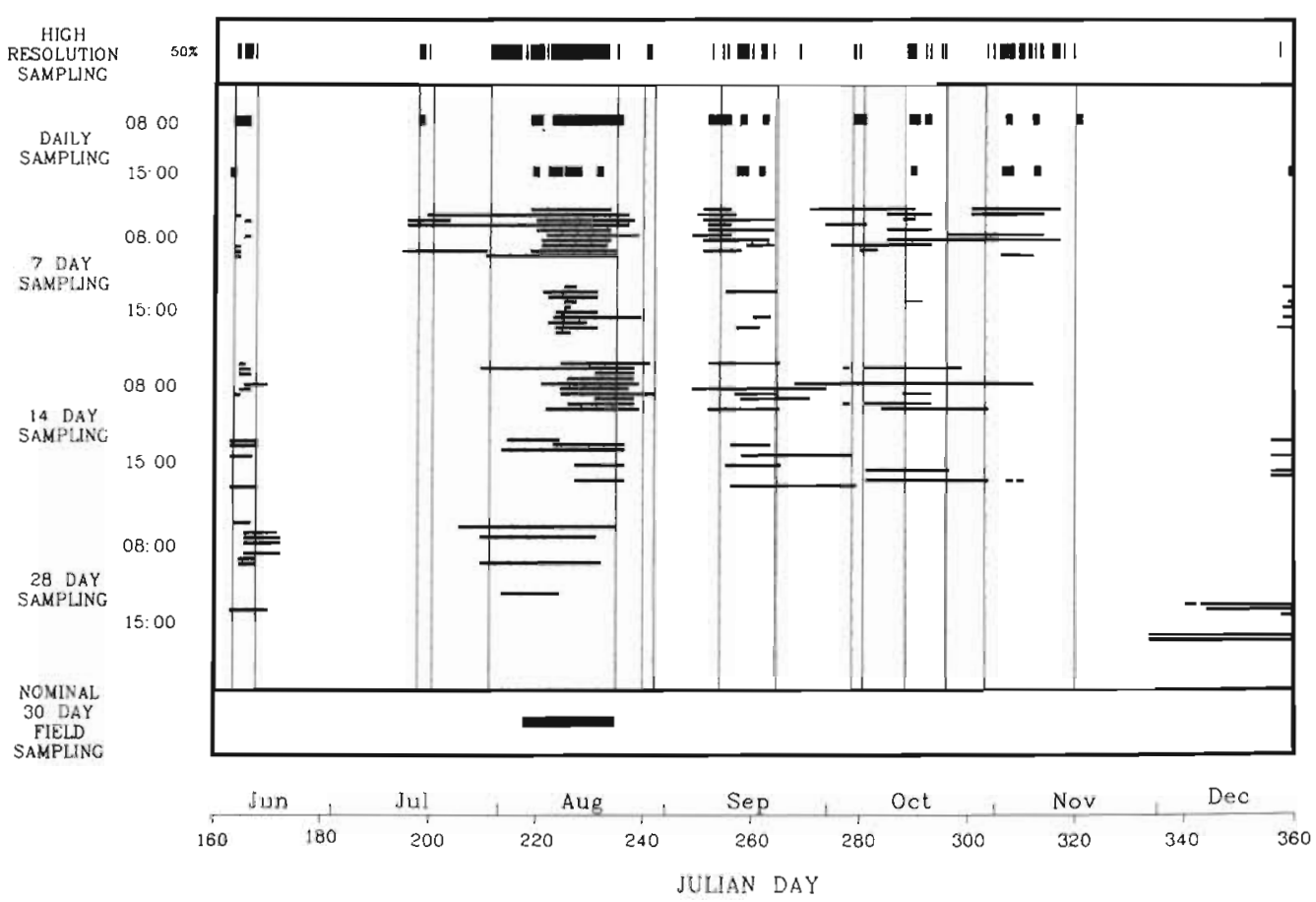

Fig. 5. Effect of sampling interval upon estimates of the duration of oxygen depletion. Solid bars (top row) and the shaded vertical areas below delineate the periods when bottom water oxygen was equal to or below $50 \%$ of atmospheric equilibrium as determined from high-resolution data taken at 15 min intervals. Thin bars (below) represent simular periods determined from lowerresolution data obtained by subsampling the high-density data set at the indicated intervals and time of day in a manner similar to the photosynthesis study. For the 7, 14 and 28 d sampling periods the data extraction process was repeated 10 times to simulate results obtained as if 10 independent laboratories had conducted analyses at the indicated sampling interval plus or minus an up to $2 \mathrm{~d}$ randomly selected variability in the exact day of sampling. The horizontal bar at the bottom represents the period of oxygen depletion determined from an independent nominal monthly monitoring program (O, in Fig. $3 \mathrm{C})$

Results indicate that the major periods of depletion (oxygen $<50 \%$ of atmospheric equilibrium; delineated by shaded regions) are reliably detected only if sampling intervals of $1 \mathrm{~d}$ or less are employed $(7$ of 8 hypoxic events detected using 08:00 h data). The time of day that the analysis was performed also influenced results. For example, sampling near 08:00 h typically resulted in lower measured bottom water oxygen content, primarily from night-time respiration, and, hence, longer periods of apparent oxygen stress (i.e. longer horizontal bars). On the other hand, sampling at 15:00 $\mathrm{h}$ emphasized effects of the resupply of oxygen by daytime photosynthesis (e.g. Nixon \& Oviatt 1973) significantly enhancing oxygen content by the afternoon (see Fig. 3C, small panel). This often resulted in shorter periods of perceived oxygen stress.

At what would traditionally be considered an intensive sampling frequency ( $7 \mathrm{~d}$ intervals) only the major oxygen depletion event associated with the bloom was detected $100 \%$ of the time (10 out of 10 of the hypothetical cases) and was insensitive to the hour of sampling. Because of large amplitude, short duration fluctuations in oxygen after September, weekly sampling resulted in both over- and underestimation of the dura- tion of oxygen depletion events in the latter portion of the season. At longer sampling intervals reliable assessment of oxygen status further deteriorated. With extension of the sampling intervals to $28 \mathrm{~d}$, the approximate interval typically used in water quality monitoring programs (cf. Malone 1991, Parker \& O'Reilly 1991), detection of even major depletion events is largely a matter of chance, as was perhaps the case with the independent field study conducted at nominal $30 \mathrm{~d}$ intervals (Fig. 3C, open circles; Fig. 5, lower horizontal bar). Only 3 of 10 of the hypothetical morning studies, for example, would have detected the major bloom event. Even more striking is that afternoon studies would have detected no major oxygen stress periods, or may have indicated long-term stress at the wrong time of year (an exaggeration resulting from the detection of an incidental $4 \mathrm{~h}$ afternoon low oxygen event that occurred in late December).

High-frequency variability in water column oxygen is not restricted solely to small enclosed eutrophic embayments. A portion of the results from a near-shore station in Buzzards Bay is shown in Fig. 6B in comparison with Little Pond (Fig. 6A). At a station $2 \mathrm{~km}$ from shore, short-term temporal fluctuations in bottom 

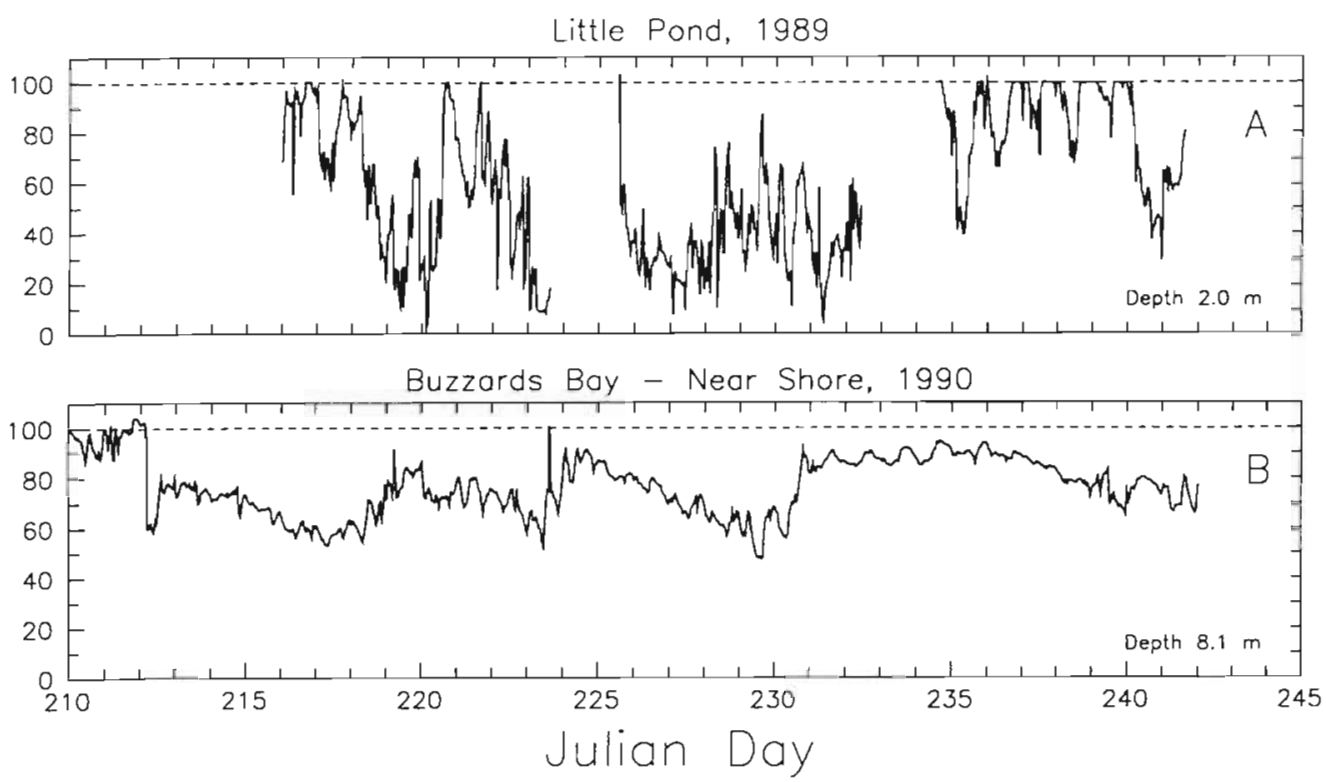

Fig. 6. Oxygen dynamics in Little Pond and near-shore locations in Buzzards Bay. Percent oxygen saturation was determined from the ratio of measured oxygen concentration and atmospheric equilibrium oxygen concentration computed as described in the 'Methods'

water oxygen content ranging between 100 and $60 \%$ of saturation were observed. Time series records (data not shown) suggested a correlation between oxygen depletion and water temperature, wind speed and wind direction $\left(r^{2}=0.83, p<0.05\right)$. The relationship appeared to result from the role these variables play in water column stratification. Lower oxygen was associated with temperature and wind conditions that would result in decreased vertical mixing. Oxygen depletion events developed in 1 to $5 \mathrm{~d}$, persisted for a few days and rapidly dissipated in 1 to $2 \mathrm{~d}$ as the entire water column again became vertically mixed. Though the magnitude of fluctuations in water column oxygen was less than that observed in Little Pond, an adequate description of oxygen status in mesotrophic coastal waters still requires a minimum sampling period on the order of $1 \mathrm{~d}$, rather than the 14 to $30 \mathrm{~d}$ sampling program typically undertaken (Dauer et al. 1992). Results from a recent study in Chesapeake Bay (Sanford et al. 1990) also support this conclusion, where high-resolution measurements showed that variability in dissolved oxygen was large (spanning approximately $190 \mu \mathrm{M}$ ), spatially heterogeneous, and occurred on time scales ranging from several days to less than an hour.

\section{CONCLUSIONS}

A well-established requirement for sensing variable phenomena by discrete sampling is that the frequency of the measurement must be at least twice that of the most frequent significant event (Chatfield 1984). Data presented here indicate that if classic sampling is employed in near-shore coastal marine environments this rule will often be disobeyed. Intensive sampling in the traditional sense (14 to $30 \mathrm{~d}$ intervals) still includes significant error and is therefore inadequate for the quantitative ecological studies necessary for determining the linkages between nutrient dynamics and effects upon primary production and water column oxygen status. The sampling regime dictated by many coastal ecosystems clearly appears to exceed the logistical capability of laboratory- or ship-based studies. One solution is to emphasize instrumental approaches that can attain essential high-density data without the concomitant increases in cost that would result from merely increasing sampling frequency using traditional methods.

Acknowledgements. This is WHOI contribution number 8044 . We thank M. Sebert for his technical assistance with time series SID incubations and oxygen measurements, $M$. Bryson for conducting bottle photosynthesis measurements, N. Millham for help with oxygen measurements, and D. Schlezinger for measurements of sediment and water column respiration rates. This research was supported by the National Oceanic and Atmospheric Administration, Sea Grants NA86-AA-DSG090 R/B-95-PD and R/P-34; NA90-AA-D-SG480 R/P-38.

\section{LITERATURE CITED}

Benson, B. B. Krause, D. Jr (1984). The concentration and isotopic fractionation of oxygen dissolved in freshwater and seawater in equilibrium with the atmosphere. Limnol. Oceanogr. 29: 620-632

Boynton, W. R., Kemp, W. M., Keefe, C. W. (1982). A comparative analysis of nutrients and other factors influencing estuarine phytoplankton production. In: Kennedy, V. S. (ed.) Estuarine comparisons. Academic Press, New York p. $69-90$

Chatfield, C. (1984). The analysis of time series, an introduction. Chapman \& Hall, New York, p. 131 
Cole, J. J., Caraco, N. F., Strayer, D. L., Ochs, C., Nolan, S. (1989). A detailed organic carbon budget as an ecosystemlevel calibration of bacterial respiration in an oligotrophic lake during midsummer. Limnol. Oceanogr. 34: 286-296

Costa, J. E., Howes, B. L., Giblin, A. E., Valiela, I. (1992). Monitoring nitrogen and indicators of nitrogen loading to support management action in Buzzards Bay. In: Hyatt, D. E., McDonald, V J. (eds.) Ecologial indicators, Vol. 1. Elsevier Applied Science, New York, p. 400-531

Dauer, D. M., Rodi, A. J., Ranasinghe, J. A. (1992). Effects of low dissolved oxygen events on the macrobenthos of the lower Chesapeake Bay. Estuaries 15: 384-391

Dickey, T D. (1990). Physical-optical-biological scales relevant to recruitment in large marine ecosystems ln: Sherman, K., Alexander, L. M., Gold, B. D. (eds.) Large marine ecosystems, patterns, processes, and yields. American Association for the Advancement of Science, Washington, D.C., p. $82-98$

Dickey, T. D. (1991). The emergence of concurrent highresolution physical and bio-optical measurements in the upper ocean and their applications. Rev. Geophys. 29: $383-413$

Dickey, T D., Granata, T., Marra, J., Langdon, C., Wiggert, J., Chai, Z., Hamilton, M., Vasquez, J., Stramska, M., Bidigare, R., Siegel, D. (1993). Seasonal variability of bio-optical and physical properties in the Sargasso Sea. J. geophys. Res. 98: 865-898

Dustan P., Pinckney, J. L. Jr (1989). Tidally induced estuarine phytoplankton patchiness. Limnol. Oceanogr. 24: 410-419

Jenkins, W. J., Goldman, J. C. (1985). Seasonal oxygen cycling and primary production in the Sargasso Sea. J. mar. Res. 43: 465-491

Langdon, C. (1984). Dissolved oxygen monitoring system using a pulsed electrode: design, performance, and evaluation. Deep Sea Res. 31.1357-1367

Lewis, M. R., Platt, T. (1982). Scales of variability in estuarine ecosystems. In: Kennedy, V. S. (ed.) Estuarine comparisons. Academic Press, New York, p. 3-20

Lohrenz, S. E. (1985). Primary production of particulate protein amino acids: algal protein metabolism and its relationship to the composition of particulate organic matter. Doctoral Dissertation, Woods Hole Oceanographic Institution and Massachusetts Institute of Technology

Lohrenz, S. E., Knauer, G. A., Asper, V. L., Tuel, M., Michaels, A. F. Knap, A. H. (1992). Seasonal variability in primary production and particle flux in the northwestern Sargasso Sea: U.S. JGOFS Bermuda Atlantic Time-series Study. Deep Sea Res. 39: 1373-1391

Lohrenz, S. E., Taylor, C. D., Howes, B. L. (1987). Primary production of protein. II. Algal protein metabolism and its relation to particulate organic matter decomposition in the

This article was presented by D. A. Caron (Senior Editorial Advisor), Woods Hole, Massachusetts, USA surface mixed layer. Mar. Ecol. Prog. Ser. 40: 175-183

Malone, T. C. (1991). River flow, phytoplankton production and oxygen depletion in Chesapeake Bay. In: Tyson, R. V., Pearson, T. H. (eds.) Modern and ancient continental shelf anoxia. Geol. Soc. Spec. Publ. No. 58: 83-93

Mantoura, R. F. C., Owens, N. J. P., Burkill, P. H. (1988). Nitrogen biogeochemistry and modeling of Carmarthen Bay. In: Blackburn, T H., Sorensen, J. (eds.) Nitrogen cycling in coastal marine environments. John Wiley, New York, p. $415-441$

Mills, D. K., Tett, P. B. (1990). Use of a recording fluorometer for continuous measurement of phytoplankton concentration. SPIE Proceedings: Environment and Pollution Measurement Sensors and Systems. 1269: 106-115

Nixon, S. W. Oviatt, C. A. (1973). Ecology of a New England salt marsh. Ecol. Monogr. 43: 463-498

Nixon, S. W. Pilson, M. Q. (1983). Nitrogen in estuarine and coastal marine ecosystems. In: Carpenter, E. J., Capone, D. G. (eds.) Nitrogen in the marine environment. Academic Press, New York, p. 565-648

Nixon, S. W., Oviatt, C. A., Frithsen, J, Sullivan, B. (1986). Nutrients and the productivity of estuarine and coastal marine ecosystems. J. Limnol. Soc. S. Afr. 12: 43-71

O'Reilly, J. E., Busch, D. A. (1984). Phytoplankton primary production on the northwestern Atlantic shelf. Rapp. P.-v. Réun. Cons. int. Explor. Mer 183: 255-268

Oviatt, C. A., Keller, A. A., Sampou, P. A., Beatty, L. L. (1986). Patterns of productivity during eutrophication: a mesocosm experiment. Mar. Ecol. Prog. Ser. 28: 69-80

Parker, C. A., O'Reilly, J. E. (1991). Oxygen depletion in Long Island Sound: a historical perspective. Estuaries 14: $248-264$

Parsons, T R., Maita, Y., Lalli, C. M. (1984). A manual of chemical and biological methods for seawater analysis. Pergamon Press, New York

Rizzo, W. M., Wetzel, R. L. (1986). Temporal variability in oxygen metabolism of an estuarine shoal sediment. In: Wolfe, D. A. (ed.) Estuarine variability. Academic Press, New York, p. 227-239

Sanford, L. P., Sellner, K. G., Breitburg, D. L. (1990). Covariability of dissolved oxygen with physical processes in the summertime Chesapeake Bay. J. mar. Res. 48: 567-590

Taylor, C. D., Doherty, K. W. (1990). Submersible Incubation Device (SID), autonomous instrumentation for the in situ measurement of primary production and other microbial rate processes. Deep Sea Res. 37: 343-358

Wiggert, J., Dickey, T., Granata, T (in press). The effect of undersampling on primary production estimates. J. geophys. Res.

Zar, J. H. (1974). Biostatistical analysis, Prentice-Hall, Inc., Englewood Cliffs, NJ

Manuscript first received: June 1, 1993

Revised version accepted: February 10, 1994 